\title{
Experimental Estimation of the Turbulent Energy Dissipation Rate in the Sea Subsurface Layer at Storm Conditions
}

\author{
A. M. Chukharev*, A. G. Zubov, O. I. Pavlenko \\ Marine Hydrophysical Institute, Russian Academy of Sciences, Sevastopol, Russian Federation \\ *e-mail: alexchukh@mail.ru
}

\begin{abstract}
Rate of the turbulent energy dissipation arising due to the breaking surface waves is estimated based on the experimental data on near-surface turbulence. The studies were carried out on the oceanographic platform in the Black Sea coastal zone by the specialized measuring complex "Sigma1". To analyze the data, specific hydrometeorological conditions including high wind speed and significant number of breaking waves were chosen from the total data array. The turbulent energy dissipation rate per unit of volume $\varepsilon$ is calculated using the spectra of velocity fluctuations based on the Kolmogorov hypotheses on the inertial-range spectrum of turbulence. The dissipation rate per unit of area of the sea surface is calculated by the over depth integrating the values of $\varepsilon$ defined on all the measurement horizons with their extrapolation up to the surface and bottom. The results provided by the experimental data are compared to the wave energy losses due to breaking calculated by the Phillips model (1985). The values of the breaking parameter $b$ calculated under the assumption on its model dependence upon the wave number are smaller than the estimates obtained by the other authors. The second method of calculation implies an assumption that the breaking parameter is constant in every single experiment and does not depend on the wave number. The obtained values of $b$ are of moderate spread and also smaller (within one order of magnitude) than the estimates obtained by the other authors. In this case the values of $b$ are satisfactorily approximated by the constant $b_{c} \approx 1.31 \cdot 10^{-4}$. Discrepancy between the obtained results and those in the other sources can be conditioned by the differing waves' characteristics and methods for estimating the dissipation rate.
\end{abstract}

Keywords: breaking of waves, marine turbulence, turbulent energy dissipation, field measurements.

Acknowlegement: the study is carried out within the framework of the State Order No.0827-20180003 under the RFFI financial support; Project No. 16-05-00664.

For citation: Chukharev, A.M., Zubov, A.G. and Pavlenko, O.I., 2018. Experimental Estimation of the Turbulent Energy Dissipation Rate in the Sea Subsurface Layer at Storm Conditions. Physical Oceanography, [e-journal] 25(4), pp. 305-316. doi:10.22449/1573-160X-2018-4-305-316

DOI: $10.22449 / 1573-160 X-2018-4-305-316$

(c) 2018, A. M. Chukharev, A. G. Zubov, O. I. Pavlenko

(C) 2018, Physical Oceanography

\section{Introduction}

Diversity of processes and the complex interrelationships between them in the conjugated layers of the ocean and the atmosphere are the reason that the reliable parametrization of the interaction of two environments under different hydrometeorological conditions is still far from being completed. Turbulence in the near-surface layer of the sea has a significant effect on the redistribution of heat, momentum and various dissolved substances. The large variability of the external conditions and the dependence of the turbulent exchange intensity on a variety of factors are an obstacle to the construction of accurate quantitative relationships that would confidently permit to calculate the turbulent flows near the surface. Various turbulence generation mechanisms existing in the upper layer of the ocean give a different contribution to turbulent exchange, depending on the hydrometeorological situation. 
In [1] it is noted that breaking of the surface waves is one of the most powerful sources of turbulence in the upper layer of the ocean. This essentially non-linear process is the main mechanism of wave energy loss, which limits their growth, while part of the wave energy is directly transformed into the energy of turbulence and drift current.

Plunging and spilling breakers are usually distinguished in the deep water. In the first case, the breaking part of the fluid falls to the front slope of the wave at some distance from the crest, in the second one the fluid rolls down the front slope, forming a characteristic "white caps". Spilling breakers can lose up to $10 \%$ of the basic energy of the wave, passing into turbulence and air bubble weighing, this value increases to $25 \%$ or more for plunging breakers [2].

Different authors proposed various criteria for breaking of waves:

- kinematic ones, taking into account the phase velocity of the wave and the velocity of particles [3];

- geometric ones, based on the change in the profile of the wave in the process of its development [2];

- dynamic ones, where such wave characteristics as the crest acceleration, the momentum and energy growth rate, as well as the evolution of the energy of higher harmonics are considered [2, 4].

Possible mechanisms leading to breaking of waves in the open ocean are classified in [5]. These include the wave-wave interaction, energy convergence, the interaction of waves and currents, etc. It is assumed that, depending on the conditions of breaking occurrence, their dynamics may differ. No studies have been carried out in this field, and the aforementioned aspects are not considered in the present work.

Depending on the dominant mechanism of turbulence generation in the nearsurface layer, the turbulence energy distribution in depth will be different. Currently, the most objective characteristic of the turbulence intensity is the turbulent energy dissipation rate $\varepsilon$. Its value can be experimentally determined based on direct measurements of turbulent pulsations. For this reason, the value of $\varepsilon$ is usually compared with the theoretical estimates. It is defined as

$$
\varepsilon=\frac{v}{2} \overline{\left(\frac{\partial u_{i}^{\prime}}{\partial x_{j}}+\frac{\partial u_{j}^{\prime}}{\partial x_{i}}\right)^{2}},
$$

where $v$ is the kinematic viscosity; $u^{\prime}$ are the velocity pulsations, $i, j=1,2,3$.

In $[6,7]$ penetration depth of the breaking part of waves of different types was estimated using the theory of turbulent jets. It was determined that this depth is within 3-4h, where $h$ is the mean height of waves.

One of the most cited studies on the enhanced dissipation of turbulent kinetic energy near the sea surface are the works [8-10]. In these works, it is shown that the dissipation levels exceed those given by the analogy of the wall boundary layer at depths less than $10 H_{\mathrm{s}}$. The authors of [8] approximated their data by the curve

$$
\frac{\varepsilon H_{\mathrm{s}} \rho_{\mathrm{w}}}{F_{\mathrm{TD}}}=0,3\left(\frac{\mathrm{z}}{H_{\mathrm{s}}}\right)^{-2},
$$


where $H_{\mathrm{s}}$ is the height of the significant waves; $\rho_{\mathrm{w}}$ is the water density; $F_{\mathrm{TD}}$ is energy input from the wind; the depth $z$ is measured from the mean sea level. From the surface to the depth $0.6 H_{\mathrm{s}}$ a layer with a constant value of dissipation was assumed. This depth was set based on the dissipation integrated throughout the water column was equal to the energy input from the wind. On the basis of these studies, the most realistic until recently was the three-layer dissipation distribution scheme: in the uppermost layer, $\varepsilon$ is approximately constant and is determined by the action of breaking of waves, an intermediate layer, or a transport layer, is below, where $\varepsilon \sim z^{-2}$, and even lower $-\varepsilon$ dependence on the depth becomes analogous to the wall boundary layer: $\varepsilon \sim z^{-1}[6]$. Depth of the upper zone $Z_{\mathrm{b}} \approx 0,6 H_{\mathrm{s}}$, approximately half of the total dissipated energy is lost here, the depth of the transfer zone is $8,3<z_{t} / H_{s}<13$.

A number of experimental studies conducted in recent years in Scripps Institution of Oceanography, California, USA, make a significant contribution to the study of the turbulence features caused by the effect of surface waves breaking. In [11-13] and others, various aspects of wave breaking were considered, experimental estimates of the parameters characterizing the energy losses of the wave and the transformation of this energy into turbulence were made. From the results of these studies it also follows that near the sea surface enhanced turbulent energy values are observed.

In contrast to [8] and [10] in [13], the dissipation scaling was carried out using the wave dissipation $F_{\mathrm{ds}}$, which is defined as

$$
F_{\mathrm{ds}}=\rho_{\mathrm{w}} g \int S_{\mathrm{ds}}(k, \theta) k d k d \theta,
$$

where $S_{\mathrm{ds}}$ is the dissipated part of the energy in the wave spectrum; $k$ is the wave number; $\theta$ is the angle of the wave propagation. The decision to use $F_{\mathrm{ds}}$ instead of $F_{\mathrm{TD}}$ is due to the fact that $F_{\mathrm{ds}}$ is a more accurate measure of energy loss by the wave field at large wave-age values $c_{\mathrm{p}} / u_{*}$, which were observed during the experiments described in [13]. At low values $c_{\mathrm{p}} / u_{*}=13-29$ (in this range the experiments $[8,10]$ were carried out) $F_{\mathrm{ds}}$ and $F_{\mathrm{TD}}$ values turned out to be close [13]. At the depth $z / H_{\mathrm{s}}>0.6$ measured dissipation profiles in [13] approximately corresponded to the dependence $z^{-2}$, obtained in [10]. However, the scatter was significant and in measurements [13] the $\varepsilon$ values appeared to be lower than in [10], at least at the depths $O\left(H_{\mathrm{s}}\right)$. This is apparently explained by different frames of reference, since in [13] the depth was measured from the instantaneous surface. At the depth higher $0.6 H_{\mathrm{s}}$ the results [13] showed a change in the dissipation profile as $z^{-1}$. This does not contradict the data of $[8,10]$, since measurements in this depth region were not carried out. Recent studies also did not show a constant value of $\varepsilon$, assumed in [8, 10]. In [14] the dissipation profile $z^{-1}$ was determined in the depth range of $0,3 H_{\mathrm{s}}-2 \mathrm{H}_{\mathrm{s}}$. However, the dependence obtained did not correspond to the classical wall boundary analogy

$$
\varepsilon_{\mathrm{wl}}=\frac{u_{*_{\mathrm{w}}}^{3}}{\kappa Z},
$$


but exceeded it 5-20 times. Here $\kappa$ is the von Karman constant; $u_{*_{\mathrm{w}}}$ is the friction velocity in water. In [14] it was found that the highest relation $\varepsilon / \varepsilon_{\mathrm{wl}}$ was observed under weak winds, the lowest - under strong ones.

Despite the remarkable progress in studying the complex phenomenon of wave breaking, there are no generally accepted methods for calculating turbulence energy due to the effect of the breaking. Issue on the values of the parameters in the formulas for calculating the characteristics of the breaking waves remains unclear [15].

The aim of the present paper is to estimate experimentally the turbulent energy dissipation rate under breaking waves, to determine the breaking parameter in the Phillips model [15] and to compare it with the estimates of other authors, who also take this model as a basis.

\section{Theoretical model}

In the fundamental work of Phillips [15], devoted to the spectral description of wind waves and statistical characteristics of breaking, a dimensional parameter was introduced to estimate the breaking intensity $\Lambda(c) d c$, which is the length of the breaking front per area unit of the sea surface in the phase velocity range of waves from $c$ to $c+d c$ :

$$
L=\int \Lambda(c) d c,
$$

here $L$ is the total length of the breaking fronts per unit of the sea surface. In a unit of time, the proportion of the sea surface occupied by the passing breaking fronts is determined through the first moment $\Lambda(c)$ [15]:

$$
R=\int c \Lambda(c) d c .
$$

At that estimation of the mean rate of energy loss by a breaker at speeds from $c$ to $c+d c$ per area unit is determined through the fifth moment by the formula [15]:

$$
\varepsilon_{\mathrm{s}}(c) d c=b g^{-1} c^{5} \Lambda(c) d c,
$$

where $\varepsilon_{s}(c) d c$ is the mean energy loss per unit area; $b$ is the dimensionless parameter, characterizing the breaking intensity; $g$ is the free fall acceleration. Phillips considered $b$ as a constant, but in the laboratory experiments [16, 17], and also based on the in situ measurements [11] $b$ was shown to be inconstant and moreover, varying within the range up to three orders of the values. Based on the specialized experiments described in [11], the following model formula for the dependence of this parameter on the wave number was suggested:

$$
b(k)=A_{1}\left[B(k)^{1 / 2}-B_{T}^{1 / 2}\right]^{5 / 2},
$$

where $A_{1}$ and $B_{T}$ are constants; $B(k)$ is the an azimuth-integrated spectrum of saturation of surface waves, introduced by Phillips [15]:

$$
B(k)=\int F(\mathbf{k}) k^{4} d \theta,
$$

here $\mathbf{k}$ is the wave vector; $F(\mathbf{k})$ is the spatial wave spectrum. The wave spectrum along the directions and wave numbers is defined as 


$$
\left\langle\eta^{2}\right\rangle=\int F(k, \theta) k d k d \theta
$$

where $\eta$ is the displacement of the surface from the equilibrium position, the angle brackets are averaging over space. Calculation of the saturation spectrum is carried out by the following relation [11]:

$$
B(k)=a_{\mathrm{k}}^{2} k^{2} \frac{k}{\delta k},
$$

where $a_{\mathrm{k}}$ is the spectral component of the wave for a given wave number $k$; $\delta k$ is the spectral resolution.

Taking into account the dispersion relation for gravitational waves in deep water $\omega^{2}=g k$ and the expression for the phase velocity $c^{2}=g / k$, it is possible to go to the phase velocity $(c)$ scale in dependence (7).

In [12], based on full-scale experiments, the form of the function $\Lambda(c)$ was determined. For $c>c_{\mathrm{p}}$ this distribution is described by a power function of the phase velocity of the waves and depends on the wave height and the phase velocity of the spectral peak:

$$
\begin{gathered}
\Lambda(c) c_{\mathrm{p}}^{3} g^{-1}\left(\frac{c_{\mathrm{p}}}{u_{*_{\mathrm{w}}}}\right)^{0,5}=0,05 \hat{c}_{\mathrm{p}}^{-6}, \\
\hat{c}_{\mathrm{p}}=\left(\frac{c}{\sqrt{g H_{\mathrm{s}}}}\right)\left(\frac{g H_{\mathrm{s}}}{c_{\mathrm{p}}^{2}}\right)^{0,1},
\end{gathered}
$$

where $H_{\mathrm{s}}=4 \sigma$ is the height of the significant waves ( $\sigma$ is the standard deviation of the sea surface from the equilibrium position); $c_{\mathrm{p}}$ is the phase velocity of the spectral peak of the wave. The friction velocity is calculated through the wind speed:

$$
u_{*_{\mathrm{w}}}=\left(\frac{\rho_{\mathrm{a}} C_{\mathrm{D}}}{\rho_{\mathrm{w}}}\right)^{1 / 2} V_{10} .
$$

Here $\rho_{\mathrm{a}}$ and $\rho_{\mathrm{w}}$ are the air and water density, respectively; $C_{\mathrm{D}}$ is the surface drag coefficient, usually determined by the empirical formula

$$
C_{\mathrm{D}}=0,001\left(0.75+0,067 V_{10}\right) \text {. }
$$

By $V_{10}$ the wind speed at a height of $10 \mathrm{~m}$ is indicated.

Thus, using the model and empirical relationships described, the energy flux from the breaking waves in (6) can be estimated and compared with the present experimental data on the turbulence intensity in the near-surface layer.

\section{In situ measurements}

For a number of years, the staff of the Turbulence Department of Marine Hydrophysical Institute (MHI) of the Russian Academy of Sciences carried out insitu measurements of turbulent characteristics in the near-surface layer of the sea, including under storm conditions and in the presence of breaking waves. The measurements were carried out on the stationary oceanographic platform of the PHYSICAL OCEANOGRAPHY VOL. 25 ISS. 4 (2018) 
Black Sea Hydrophysical Polygon, RAS in Katsiveli (Crimea). A positional variant of the Sigma-1 measuring complex was used [18], the general view of which is shown in Fig. 1.

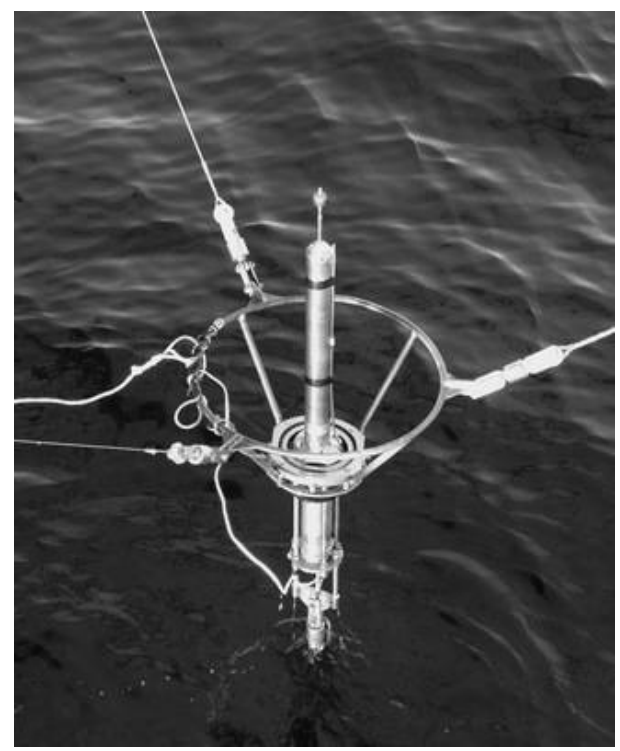

Fig. 1. General view of positional variant of the Sigma-1 measuring complex

The device hull construction and specially designed positioning system [19] allow the instrument to be fixed on the selected horizon from the surface to a depth of $\sim 20 \mathrm{~m}$, minimizing its own oscillations. In this case, the entire system is weighted by a load below the instrument at a distance of $4 \mathrm{~m}$ to exclude its effect on the measurements. The measuring complex includes a position control system that registers the instrument's own movements. This allows special processing to remove parasitic oscillations from the records, which cannot be mechanically completely avoided [20]. The measuring complex by means of a communication cable is connected to the onboard receiving instrument. The registration and accumulation of the information obtained is carried out by a personal computer in real time. The instrument is placed in the seaward side of the platform, which eliminates the effect of its supports on the measurement area, i. e., it provides data obtaining in the natural environment. According to specially performed studies, the wave characteristics in the area of the platform can be considered to correspond to the conditions of the open sea under the current and waves moving from a certain azimuth sector [21].

The turbulent energy dissipation rate $\varepsilon$ was calculated by the method proposed in [22] and described in [1]. At the same time, the distortions introduced into the measured signal by the waves and oscillations of the device do not have a significant effect on the result. In the same way, the dissipation rate was determined in [23]. The method was developed taking into account Kolmogorov's hypothesis about the inertial range of the turbulence spectrum, in accordance with this hypothesis the spectral density of velocity pulsations can be represented in the following form 


$$
E(k)=\varepsilon^{1 / 4} v^{5 / 4} F(\lambda),
$$

where $F(\lambda)$ is the universal function (model spectrum); $\lambda=k /\left(\varepsilon^{1 / 4} v^{-3 / 4}\right)$ is the dimensionless wave number. The dissipation rate was determined from the condition of the best agreement between the experimental and model spectra, the kinematic viscosity was calculated from the measured temperature and salinity, and the Nasmite spectrum was used as the model one [24]. The measured values of velocity pulsations were first processed by a median filter, a frequency spectrum was calculated from them, which was then recalculated into the wave number spectrum according to the "frozen turbulence" hypothesis of Taylor: $U_{\mathrm{d}}=\omega / \mathrm{k}$, where $U_{\mathrm{d}}$ is the speed of turbulent eddy transfer through the sensor; $\omega$ is the angular frequency. The mean velocity of the main current was taken as the transport velocity. For comparison, the values of $\varepsilon$ calculated from the vertical velocity pulsations were used, since it is the least subject to the effect of the own oscillations of the device.

The storm conditions were chosen for the analysis from the entire data array with a large number of breaking waves, which mainly were of the spilling type. Basic hydrometeorological conditions in these experiments are shown in Tab. 1.

Table 1

\section{Basic hydrometeorological conditions during the field measurements chosen} for analysis

\begin{tabular}{c|c|c|c|c|r}
\hline Date & Local time & $V_{10}, \mathrm{~m} / \mathrm{s}$ & $H_{\mathrm{s}}, \mathrm{m}$ & $V_{10} / c_{\mathrm{p}}$ & $f_{\mathrm{p}}, \mathrm{Hz}$ \\
\hline 26.09 .2008 & $14: 43-17: 01$ & 15.4 & 1.6 & 1.58 & 0.16 \\
27.09 .2008 & $10: 51-13: 09$ & 6.4 & 1.6 & 0.66 & 0.16 \\
14.10 .2009 & $09: 45-11: 43$ & 13.4 & 1.16 & 1.37 & 0.16 \\
16.10 .2009 & $10: 57-13: 31$ & 9.8 & 0.58 & 1.38 & 0.22 \\
09.10 .2013 & $16: 17-18: 01$ & 8.1 & 0.5 & 0.33 & 1.71 \\
15.10 .2013 & $16: 44-18: 05$ & 7.5 & 0.31 & 2.16 & 0.45 \\
16.10 .2013 & $15: 11-16: 25$ & 6.9 & 0.59 & 0.86 & 0.195 \\
17.10 .2013 & $11: 14-12: 28$ & 9.2 & 0.85 & 1.24 & 0.21 \\
21.09 .2015 & $12: 28-14: 04$ & 6.3 & 0.26 & 0.65 & 0.16 \\
24.09 .2015 & $09: 02-11: 13$ & 9.9 & 0.46 & 1.33 & 0.21 \\
04.06 .2017 & $10: 59-12: 52$ & 11 & 0.72 & 1.83 & 0.26 \\
05.06 .2017 & $08: 30-10: 41$ & 16 & 1.16 & 2.15 & 0.21 \\
\hline
\end{tabular}

$\mathrm{N}$ o t e: $V_{10}, \mathrm{~m} / \mathrm{s}$ is the wind speed on the $10 \mathrm{~m}$ horizon; $H_{s}, \mathrm{~m}$ is the height of significant waves, $V_{10} / c_{\mathrm{p}}$ is the reverse age of waves; $f_{\mathrm{p}}, \mathrm{Hz}$ is the spectral peak frequency of waves.

Wind speed and wave parameters were registered by the staff of MHI Remote Sensing Department by means of their own measuring equipment (Davis $6152 E U$ meteorological complex and wire wave recorder); the obtained data were kindly provided to us.

In majority of the experiments, in the presence of breaking waves, the dissipation rate was determined from $0.5-1 \mathrm{~m}$ horizon to a depth of $10 \mathrm{~m}$ with the step of $0.5-1 \mathrm{~m}$. To compare with the values calculated by the Phillips model of the energy loss of the breaking wave per unit area, the $\varepsilon$ distribution was integrated 
over the depth. Then $\varepsilon$ value, caused by the drift current velocity shear and calculated by the formula (3), was subtracted. Here it is assumed that the essential part of the energy lost by the wave dissipates at depths of up to $10 \mathrm{~m}$. The generation of turbulence by nonlinear wave motion effects in this case is neglected. Extrapolation of $\varepsilon$ dependence on the layer from the upper point of measurements to the surface was carried out on the assumption of its correspondence in this layer to the law $\varepsilon \sim z^{-1}$ [13]. The value $z_{\mathrm{b}}=2 \pi / k_{\mathrm{b}} \approx 0.05 \mathrm{~m}$ was taken as the zero surface, where $k_{\mathrm{b}}$ is the wave number of the shortest breaking waves [25].

An example of the dissipation rate distribution in depth for separate experiments is shown in Fig. 2. Also, the calculated dependence of $\varepsilon$ on the depth is given in accordance to the model for the wall boundary layer according to the formula (3). A typical wave spectrum in storm conditions in the region of a stationary oceanographic platform is shown in Fig. 3.

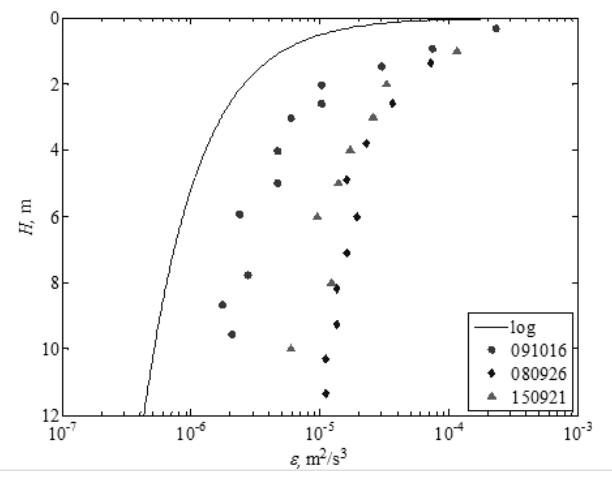

Fig. 2. Examples of the values (resulted from various experiments) of the turbulent energy dissipation rate at presence of wave breaking and theoretical dependence (3) for the data 091016

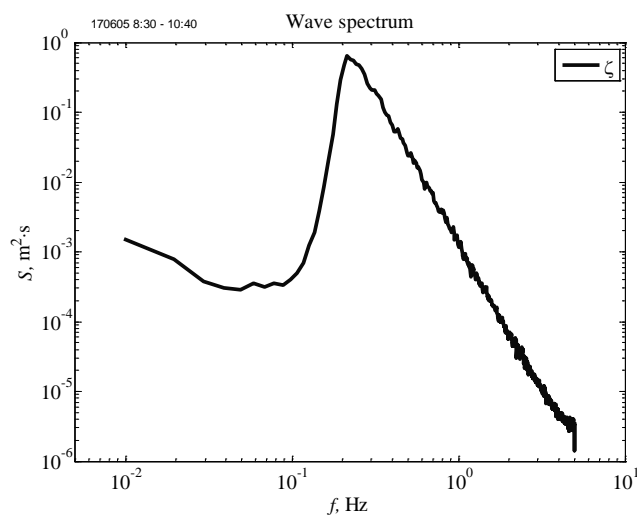

Fig. 3. Characteristic spectrum of surface waves at storm conditions. Data of 05.06.2017

The sources of possible errors in the experimental determination of $\varepsilon_{\mathrm{s}}$ (dissipation per surface unit after integration with respect to the depth) are given in Tab. 2. 
Table 2

\section{Sources of the errors arising at experimental estimating the turbulent energy dissipation rate}

\begin{tabular}{|c|c|c|}
\hline Sources of the errors & $\begin{array}{c}\text { Value of a relative } \\
\text { error, \% }\end{array}$ & $\begin{array}{l}\text { Methods of elimination } \\
\text { (diminution) }\end{array}$ \\
\hline $\begin{array}{l}\text { Error arising at calculating the } \\
\text { spectrum of the velocity } \\
\text { vertical pulsations }\end{array}$ & $\leq 20$ & $\begin{array}{l}\text { Decrease of a device intrinsic vibration, } \\
\text { increase a number of degrees of freedom } \\
\text { at calculating the spectrum }\end{array}$ \\
\hline $\begin{array}{l}\text { Error arising at measuring the } \\
\text { horizontal current velocity }\end{array}$ & $\leq 10$ & $\begin{array}{l}\text { Measurements by independent met- } \\
\text { hods (devices) }\end{array}$ \\
\hline $\begin{array}{l}\text { Turbulent energy dissipation } \\
\text { above and below the } \\
\text { measurement area }\end{array}$ & $\leq 10$ & $\begin{array}{l}\text { Increase of measurements' depth, } \\
\text { extrapolation up to the surface and } \\
\text { down to the bottom }\end{array}$ \\
\hline $\begin{array}{l}\text { Error in extrapolating the } \\
\text { dissipation rate from the upper } \\
\text { horizon of measurements up to } \\
\text { the sea surface }\end{array}$ & $\leq 5$ & $\begin{array}{l}\text { Maximum possible approach of mea- } \\
\text { surements to the surface }\end{array}$ \\
\hline
\end{tabular}

\section{Results and discussion}

In the first calculation method according to the Phillips model, the above formulas (6) - (10) were used, in the estimation of the breaking parameter $b$, in accordance to the model (7) proposed in [11], the constants $A_{1}=4,5$ and $B_{T}=$ $=9,3 \cdot 10^{-4}$ were applied.

Calculations of the dissipation rate per sea surface area unit, based on the model, taking into account the constants and the calculation method $b(k)$ proposed in [11], showed that for the Black Sea conditions these constants and the dependence for $b(k)$ apparently need the improvement. In particular, for small wave numbers, the values of $b$ in (7) often became negative, in these cases the calculation by model (7) was carried out for the spectral region, where $b>0$. This may be due to various experimental conditions and a different wave character. Thus, the proposed model (7) for $b$ is not completely universal. There is also a possibility that it is necessary to use a slightly different dependence of $\Lambda(c)$ instead of (9), (10), which was applied in this case.

Estimates of the energy loss per $\varepsilon_{\mathrm{s}}$ area unit, determined from the experimental data and from the model, as a whole, turned out to be quite close, although some experimental values could differ from the model values and from the majority of values by 1-2 orders (Fig. 4), which is apparently related to with specific physical conditions that are difficult to standardize.

In the second method of the breaking parameter estimation in the Phillips model, it was assumed that $b$ is constant in formula (6). The value of this parameter was determined from the condition for the correspondence of the model and experimental values of the dissipation rate. The results of these calculations, depending on the steepness $A k_{\mathrm{p}}$ of the waves, are shown in Fig. 5 ( $A$ is the wave amplitude and $k_{\mathrm{p}}$ is the wave number of the spectral peak). As can be seen from this figure, the estimates of $b$ show a moderate spread within one order, the values obtained can be approximated by the constant $b_{\mathrm{c}}=1,31 \cdot 10^{-4} \pm 4,84 \cdot 10^{-5}$. 


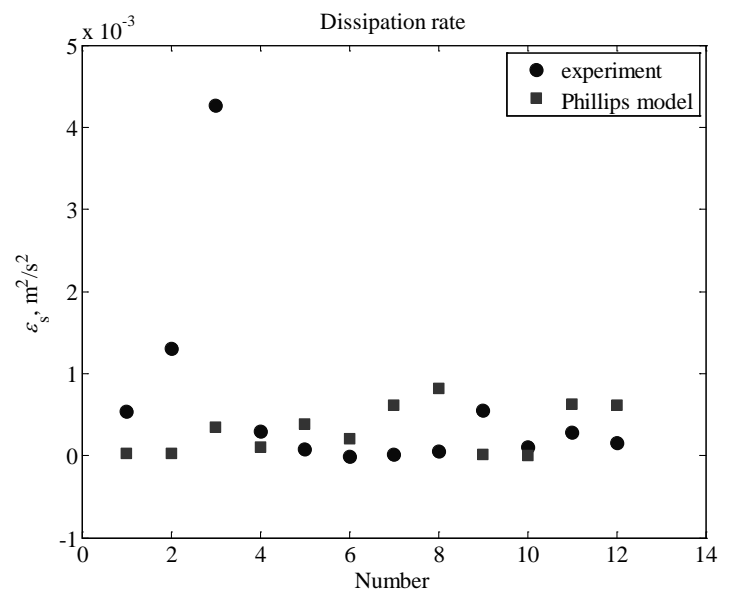

Fig. 4. Turbulent energy dissipation rate per unit of area at wave breaking. The point number on the $\mathrm{x}$-coordinate corresponds to the line number in Table 1

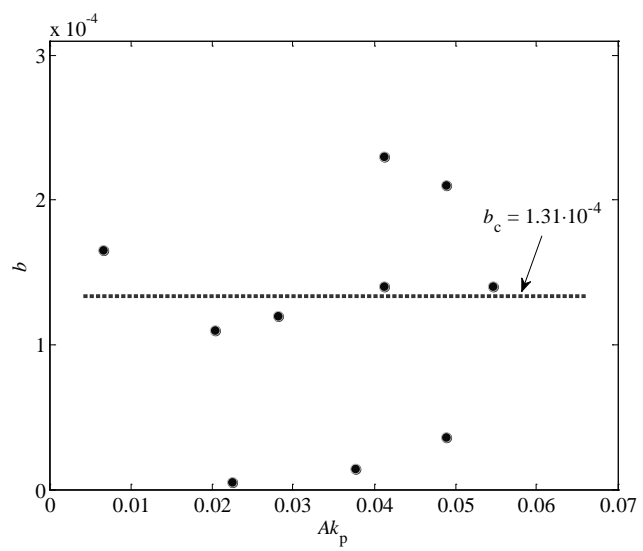

Fig. 5. Dependence of the breaking parameter on wave steepness. Points are the obtained values and $b_{\mathrm{c}}$ is the approximating constant

It should be noted that, in most cases, the calculated estimates of $b$ in the present research appear to be smaller than in the works [11, 13]. Disarrangements can be caused by a different wave, causing a change in the functional dependences (7), (9), (10), and systematic errors in determining the dissipation rate by various methods. The maximum random error in the present measurements could reach to 40-50\%. Another factor not considered here is the breaking wave energy transformation into the horizontal flow velocity - can also affect the overall estimate of $\varepsilon_{\mathrm{s}}$. In addition, turbulence generation due to micro-disturbances is taken into account in [13], although it is noted that the relatively large contribution of this phenomenon to the general dissipation of turbulent energy is concentrated mainly in a thin layer near the surface due to its small scale.

Based on the foregoing, it can be concluded that the Phillips model can be applied to estimate the energy input from breaking waves, but the dependence of the breaking parameter $b$ on the wave number and on the other wave characteristics, as well as the form of the function $\Lambda(c)$, requires further investigation. 


\section{REFERENCES}

1. Monin, A.S., Ozmidov, R.V., 1981. Okeanskaya Turbulentnost' [Oceanic Turbulence]. Leningrad: Gidrometeoizdat, 320 p. (in Russian).

2. Rapp, R.J. and Melville, W.K., 1990. Laboratory Measurements of Deep Water Breaking Waves. Philosophical Transactions of the Royal Society A: Mathematical, Physical \& Engineering Sciences, [e-journal] 331(1622), pp. 735-800. doi:10.1098/rsta.1990.0098

3. Longuet-Higgins, M.S., 1969. On Wave Breaking and the Equilibrium Spectrum of WindGenerated Waves. Proceedings of the Royal Society A: Mathematical, Physical \& Engineering Sciences, [e-journal] 310(1501), pp. 151-159. doi:10.1098/rspa.1969.0069

4. Song, J.-B. and Banner, M.L., 2002. On Determining the Onset and Strength of Breaking for Deep Water Waves. Part I: Unforced Irrotational Wave Groups. Journal of Physical Oceanography, [e-journal] 32(9), pp. 2541-2558. https://doi.org/10.1175/1520-0485-32.9.2541

5. Nepf, H.M., Wu, C.H. and Chan E.S., 1998. A Comparison of Two- and Three-Dimensional Wave Breaking. Journal of Physical Oceanography, [e-journal] 28(7), pp. 1496-1510. https://doi.org/10.1175/1520-0485(1998)028<1496:ACOTAT>2.0.CO;2

6. Chukharev, A.M., 2000. Vliyanie Obrushivayushchihsya Poverhnostnyh Voln a Turbulentnyy Obmen. Nyryayushchie Buruny [Influence of Breaking Surface Waves on Turbulent Exchange. Diving Breakers]. Morskoy Gidrofizicheskiy Zhurnal, (1), pp. 31-37 (in Russian).

7. Chukharev, A.M. and Kotovshchikov, B.B., 2000. Vliyanie Obrushivayushchihsya Poverxnostnyh Voln na Turbulentnyy Obmen. Skolzyashhie Buruny [Influence of Breaking Surface Waves on the Turbulent Exchange. Spilling Breakers]. Morskoy Gidrofizicheskiy Zhurnal, (3), pp. 13-19 (in Russian).

8. Terray, E.A., Donelan, M.A., Agrawal, Y.C., Drennan, W.M., Kahma, K.K., Williams, III A.J., Hwang P.A. and Kitaigorodskii, S.A., 1996. Estimates of Kinetic Energy Dissipation under Breaking Waves. Journal of Physical Oceanography, [e-journal] 26(5), pp. 792-807. https://doi.org/10.1175/1520-0485(1996)026<0792:EOKEDU>2.0.CO;2

9. Agrawal, Y.C., Terray, E.A., Donelan, M.A., Hwang, P.A., Williams III, A.J., Drennan, W.M., Kahma, K.K. and Kitaigorodskii, S.A., 1992. Enhanced Dissipation of Kinetic Energy Beneath Surface Waves. Nature, [e-journal] 359(6392), pp. 219-220. https://doi.org/10.1038/359219a0

10. Drennan, W.M., Donelan, M.A., Terray, E.A. and Katsaros, K.B., 1996. Oceanic Turbulence Dissipation Measurements in SWADE. Journal of Physical Oceanography, [e-journal] 26(5), pp. 808-815. https://doi.org/10.1175/1520-0485(1996)026<0808:OTDMIS>2.0.CO;2

11. Romero, L., Melville, W.K. and Kleiss, J.M., 2012. Spectral Energy Dissipation due to Surface Wave Breaking. Journal of Physical Oceanography, [e-journal] 42(9), pp. 14211444. https://doi.org/10.1175/JPO-D-11-072.1

12. Sutherland, P. and Melville, W.K., 2013. Field Measurements and Scaling of Ocean Surface Wave-Breaking Statistics. Geophysical Research Letters, [e-journal] 40(12), pp. 3074-3079. https://doi.org/10.1002/grl.50584

13. Sutherland, P. and Melville, W.K., 2015. Field Measurements of Surface and Near-Surface Turbulence in the Presence of Breaking Waves. Journal of Physical Oceanography, [e-journal] 45(4), pp. 943-965. https://doi.org/10.1175/JPO-D-14-0133.1

14. Gemmrich, J., 2010. Strong Turbulence in the Wave Crest Region. Journal of Physical Oceanography, [e-journal] 40(3), pp. 583-595. https://doi.org/10.1175/2009JPO4179.1

15. Phillips, O.M., 1985. Spectral and Statistical Properties of the Equilibrium Range in WindGenerated Gravity Waves. Journal of Fluid Mechanics, [e-journal] 156, pp. 505-531. https://doi.org/10.1017/S0022112085002221

16. Banner, M.L. and Peirson, W.L., 2007. Wave Breaking Onset and Strength for Two-Dimensional Deep-Water Wave Groups. Journal of Fluid Mechanics, [e-journal] 585, pp. 93-115. https://doi.org/10.1017/S0022112007006568

17. Drazen, D.A., Melville, W.K. and Lenain, L., 2008. Inertial Scaling of Dissipation in Unsteady Breaking Waves. Journal of Fluid Mechanics, [e-journal] 611, pp. 307-332. https://doi.org/10.1017/S0022112008002826 
18. Samodurov, A.S., Dykman, V.Z., Barabash, V.A., Efremov, O.I., Zubov, A.G., Pavlenko, O.I. and Chukharev, A.M., 2005. "Sigma-1" Measuring Complex for the Investigation of SmallScale Characteristics of Hydrophysical Fields in the Upper Layer of the Sea. Physical Oceanography, [e-journal] 15(5), pp. 311-322. https://doi.org/10.1007/s11110-006-0005-1

19. Barabash, V.A., Samodurov, A.S. and Chukharev, A.M. 2015. Izmeritelnaya Sistema dlya Issledovaniya Melkomasshtabnoi Turbulentnosti v Pripoverhnostnom Sloe Morya [Measuring System for Studying Small-Scale Turbulence in The Near-Surface Layer of the Sea]. Patent of the Russian Federation No. 2549250. Registered 26.03.2015. Published on 20.04.2015 (in Russian).

20. Chukharev, A.M., 2010. Primenenie Izmeritelnogo Kompleksa «Sigma-1» dlya Issledovaniya Turbulentnosti na Okeanograficheskoi Platforme [Using the Measuring Complex Sigma-1 for Research of Turbulence on Oceanographic Platform]. In: MHI, 2010. Ekologicheskaya Bezopasnost' Pribrezhnoi i Shel'fovoi Zon i Kompleksnoe Ispol'zovanie Resursov Shel'fa [Ecological Safety of Coastal and Shelf Zones and Comprehensive Use of Shelf Resources]. Sevastopol: MHI NANU. Iss. 21, pp. 231-238 (in Russian).

21. Dulov, V.A., Bol'shakov, A.N., Smolov, V.E., and Ivanchik, M.V., 2005. Field Study of the Space Uniformity of Meteorological and Wave Parameters in the Coastal Zone. On the Problem of Calibration of a Side-Looking Radar on the Sich-1M Satellite as an Instrument for Measuring Wind Velocity over the Sea. Physical Oceanography, [e-journal] 15(3), pp. 161-173. https://doi.org/10.1007/s11110-005-0038-X

22. Stewart, R.W. and Grant, H.L., 1962. Determination of the Rate of Dissipation of Turbulent Energy near the Sea Surface in the Presence of Waves. Journal of Geophysical Research, [e-journal] 67(8), pp. 3177-3180. https://doi.org/10.1029/JZ067i008p03177

23. Soloviev, A. and Lucas, R., 2003. Observation of Wave-Enhanced Turbulence in the Near-Surface Layer of the Ocean during TOGA COARE. Deep Sea Research Part I: Oceanographic Research Papers, [e-journal] 50(3), pp. 371-395. https://doi.org/10.1016/S0967-0637(03)00004-9

24. Oakey, N.S., 1982. Determination of the Rate of Dissipation of Turbulent Energy from Simultaneous Temperature and Velocity Shear Microstructure Measurements. Journal of Physical Oceanography, [e-journal] 12(3), pp. 256-271. https://doi.org/10.1175/15200485(1982)012<0256:DOTROD>2.0.CO;2

25. Kudryavtsev, V., Shrira, V., Dulov, V. and Malinovsky, V., 2008. On the Vertical Structure of Wind-Driven Sea Currents. Journal of Physical Oceanography, [e-journal] 38(10), pp. 2121-2144. doi:10.1175/2008JPO3883.1

About authors:

Alexander M. Chucharev - Leading Research Associate, Turbulence Department, FSBSI MHI (2 Kapitanskaya St., Sevastopol, Russian Federation, 299011), Dr.Sci. (Phys.-Math.), ORCID ID: 0000-0003-1078-6425, alexchukh@mail.ru

Anatoliy G. Zubov - Junior Research Associate, Turbulence Department, FSBSI MHI (2 Kapitanskaya St., Sevastopol, Russian Federation, 299011), sl4612@mail.ru

Olga I. Pavlenko - Leading Software Engineer, Turbulence Department, FSBSI MHI (2 Kapitanskaya St., Sevastopol, Russian Federation, 299011), SPIN-code: 9665-9290, olpav@list.ru

Contribution of the authors:

Alexander M. Chucharev - general scientific supervision of the research, development of research methods, task formulation and setting out, participation in experiments, analysis of the results, making conclusions, writing and editing of the article.

Anatoliy G. Zubov - experimental research carrying out, preparation and debugging of measuring devices, development of software to obtain the information.

Olga I. Pavlenko - development and debugging of the software for data processing and analysis, data processing, preparation of tables and graphic materials, editing and supplementing the text of the article.

All the authors have read and approved the final manuscript.

The authors declare that they have no conflict of interest. 